\title{
Changes in four complementary facets of fish diversity in a tropical coastal lagoon after 18 years: a functional interpretation
}

\author{
Julia Ramos Miranda ${ }^{1}$, David Mouillot ${ }^{2, *}$, Domingo Flores Hernandez ${ }^{1}$, \\ Atahualpa Sosa Lopez ${ }^{1}$, Thang Do Chi ${ }^{2}$, Luis Ayala Perez ${ }^{3}$
}

${ }^{1}$ Centro EPOMEX, Universidad Autónoma de Campeche, Av. Agustín Melgar s/n, Campeche, CP 24030, Campeche, México ${ }^{2}$ UMR CNRS-UMII 5119 Ecosystèmes Lagunaires, Université Montpellier II CC 093, 34095 Montpellier Cedex 5, France

${ }^{3}$ Departamento ‘El Hombre y su Ambiente', Universidad Autónoma Metropolitana, Xochimilco, CP 4960, Coyoacán, México

ABSTRACT: In a natural world increasingly transformed by human activities, the contemporary acceleration of biodiversity loss is now widely accepted. Coastal and estuarine environments are some of the most productive ecological systems on Earth and are able to provide many essential ecosystem goods and services, such as protein from fish or nutrient exports to adjacent marine ecosystems. Unfortunately, coastal lagoons are under increasing human pressure, and constraints on fish biodiversity are of major concern. Using fish samples from the Terminos coastal lagoon (southern Gulf of Mexico), we found a significant decrease in taxonomic diversity over 18 yr while variations in richness and evenness were mainly associated with seasonal and spatial variations. In other words, 2 randomly chosen individuals or 2 randomly chosen species within a fish assemblage were more likely to be closely related in the 1998 to 1999 period than in the 1980 to 1981 period. This result suggests a loss of functional diversity and a biotic homogenization in the lagoon fish community. At the same time, we observed a significant salinity increase between the 1980 to 1981 period and the 1998 to 1999 period, and the water temperature and transparency increased between the 2 annual periods. These results suggest a loss of estuarine conditions in the Terminos lagoon between the 1980 to 1981 and the 1998 to 1999 periods and a shift in hydrological conditions from hypohaline to euhaline/ hyperhaline status. In parallel, some fish families such as Mugilidae, Serranidae, Lobotidae, Achiridae, Belonidae, Elopidae and Stromatide are better represented within the Terminos lagoon now than they were in the past. As a feedback, this loss of taxonomic diversity can lead to a loss of ecological responsiveness to environmental fluctuations and a loss of ecological functioning.

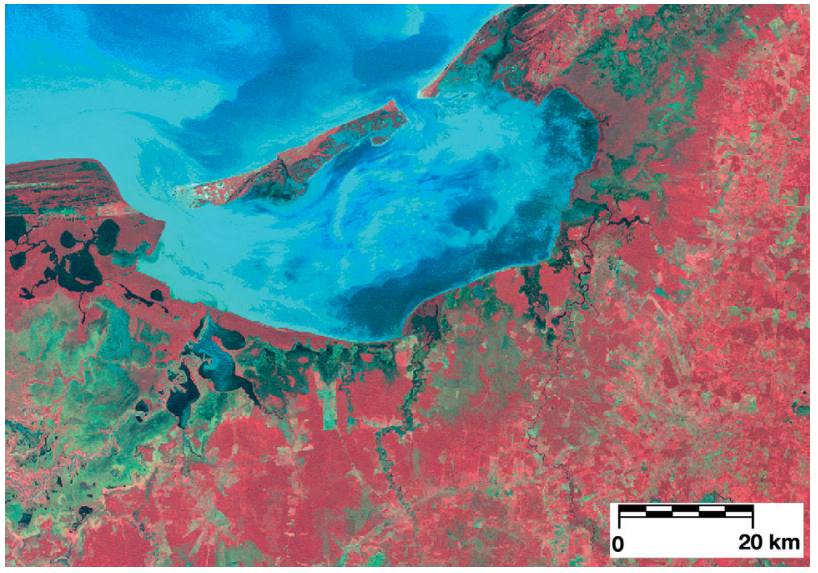

The Terminos Lagoon in the southern Gulf of Mexico is a protected area, but it is still impacted by commercial fisheries, oil extraction, and agricultural runoff. Between 1980 and 1998, salinity has increased and taxonomic diversity of fish species has decreased. This suggests a loss of functional diversity, with possible detrimental effects on the ecosystem. Red: mangroves and tropical forest. Green: agricultural areas and grass. Dark blue: low turbidity waters; light blue: high turbidity waters.

Photo: Satellite Landsat MSS (15-01-1986)

J. F. Mas (Centre EPOMEX)

KEY WORDS: Richness - Evenness - Taxonomic diversity · Community homogenization · Environmental filters · Ecological similarity · Human pressure

\section{INTRODUCTION}

The United Nations Conference on Environment and Development meeting in 1992 pointed out the urgent need to manage coastal and estuarine resources in a sustainable manner. Coastal and estuarine environments are some of the most productive ecological systems on 
Earth (Costanza et al. 1997) but are faced with increasing human pressure due to permanent and seasonal population density increase, aquaculture, fisheries and agriculture or industry on the watershed (Crooks \& Turner 1999). Thus, these coastal areas have been defined as Critical Transition Zones (CTZ) due to their position at terrestrial, freshwater and marine interfaces (Levin et al. 2001). These zones are able to provide essential ecosystem services such as shoreline protection, water quality improvement, fisheries resources, habitat and food for migratory and resident animals and recreational areas for human populations. Among these coastal zones, brackish lagoons, defined as shallow depressions located between the shore and a bar that generally allows some kind of connection with the ocean, occupy $13 \%$ of the world's coastline (Lasserre 1979). Like estuaries or coastal wetlands, they are under increasing pressure, leading to over-exploitation of resources, habitat destruction, eutrophication and pollutant contaminations (Crooks \& Turner 1999).

Fish constitute one of the main biotic component in these environments. Firstly, fish provide a valuable source of protein for human populations amounting to about $15 \%$ of our protein supply (FAO 2002). Secondly, some studies highlight the influence of fish communities on ecosystem processes through trophic relationships with other biotic components (e.g. Carrasson \& Cartes 2002). Most fish species in CTZ zones are migratory or at least non permanent residents with these zones serving as feeding or breeding areas (Levin et al. 2001). Thus fish export nutrients from coastal zones to adjacent marine ecosystems. Furthermore, fish accumulate and export pollutants from coastal lagoons (Mouillot et al. 2000). Some essential goods and services provided by coastal lagoon ecosystems are thus performed by fish species and the higher the fish biodiversity in the lagoon, the greater the number of functions can be expected to be accomplished. For example, phytoplanktivorous and predatory guilds provide different ecosystem services and are complementary. The former guild provides a secondary production and is prey for higher trophic levels whereas the latter guild often consists of migratory fishes which export biomass and thus nutrients to coastal and marine ecosystems. Moreover, the higher the fish biodiversity in the lagoon, the more varied are the biological responses during a perturbation or a crisis event. For instance, with more fish species, we can expect different biological responses to perturbations through various life-history traits or physiological abilities and thus a higher stability or resilience of the fish community inhabiting coastal zones (Bellwood et al. 2004). Thus fish diversity, known to be influenced by environmental factors or stress (e.g. Rogers et al. 1999), must certainly be carefully studied and quantified in such ecosystems.
To completely represent the biodiversity of a community by a single number is not possible (Ludwig \& Reynolds 1988). It is therefore helpful to separate biodiversity into several independent facets which can be quantified (Purvis \& Hector 2000). To summarize a community composition, the most widely used parameter is the number of species or the species richness of the sample (Gaston 1996). However, this observed species richness is an underestimation of the true species richness and the error involved will depend on sampling effort. Moreover, species richness does not take into account the distribution of individuals or abundance among species. An independent facet of biodiversity is thus species evenness (Purvis \& Hector 2000 ), i.e. whether abundances (usually density or biomass) are evenly distributed among the species. This measure of regularity in species abundances has already been used to assess environmental impacts (Airoldi \& Cinelli 1997, Hillebrand 2003). Nevertheless, species richness or evenness indices do not take into account functional, taxonomic or phylogenetic differences between species, though some authors have pointed out the necessity of including these differences between species to assess diversity (Purvis \& Hector 2000, Shimatani 2001). Since 1995, Warwick \& Clarke $(1995,1998)$ and Clarke \& Warwick $(1998,1999,2001)$ have proposed indices of taxonomic diversity that take into account the 'weighted' taxonomic differences between species. Clarke \& Warwick (2001) stressed that the taxonomic structure of an assemblage is an important facet of biodiversity, since the species number between 2 samples can be similar but with more or less taxonomically related species. According to Clarke \& Warwick (2001), little attention has been given to explaining environmental degradation effects on phylogenetic structure on local or regional scales and the extent to which properties of this structure can be used as measures of biodiversity for the purposes of biological effects monitoring. For example, Warwick \& Clarke (2001) observed a turnover of taxa in the North Sea in response to both natural variability and anthropogenic pressures, which indicates a major change in biodiversity may not be detectable as a net change in species richness. If we continue to use the traditional indices for monitoring purposes (e.g. the Shannon index), changes in biodiversity may go undetected until a very advanced stage of environmental degradation is reached (Warwick \& Clarke 2001). On the other hand, Warwick \& Clarke (1998) suggested that taxonomic and functional structure could be related in communities. This kind of relationship between functional and taxonomic diversity was supported by the study of von Euler \& Svensson (2001) on birds, and Chazdon et al. (2003) observed that patterns of trait distribution across forest types are closely 
linked with patterns of floristic composition at the genus and family levels.

The Terminos lagoon (southern Gulf of Mexico) is a lagoonal estuarine ecosystem and a critical habitat for larval and juvenile finfish species (Yáñez-Arancibia \& Day 1988) which supports commercial fisheries. Oil extraction on the adjacent continental shelf is carried out and there are also agricultural activities on the watershed. Based on the ecological and economical value of the Terminos lagoon, the Mexican government established the Terminos lagoon region as a 'Protected area for Flora and Fauna' in 1994. However, continuous development of the oil infrastructure and extraction activities, urban growth on the Carmen Island, cattle and agricultural activities, and fishing make this natural protected area difficult to manage adequately. Eighteen years after the first sampling campaign (carried out in 1980s), an important research effort was carried out in 1998 highlighting some changes in the nekton distribution and environmental conditions (Ramos Miranda et al. 2005, Sosa Lopez et al. 2005). The objective of the present study is to identify spatial and temporal changes in the species composition of the fish inhabiting Terminos lagoon based on 4 diversity indices related to 4 independent biodiversity components. A secondary objective of this paper is to link possible fish community changes with published information about environmental variation observed. Finally, functional implications of such diversity changes will be discussed.

\section{MATERIALS AND METHODS}

Data collection. Terminos lagoon is located between $90^{\circ} 00^{\prime}$ to $92^{\circ} 20^{\prime} \mathrm{W}$ and $18^{\circ} 25^{\prime}$ to $19^{\circ} 00^{\prime} \mathrm{N}$ in the Southern Gulf of Mexico (Fig. 1). The basin surface area and its average depth are $1661.50 \mathrm{~km}^{2}$ and $3.5 \mathrm{~m}$, respectively. The lagoon is connected to the sea by 2 inlets: 'Carmen Inlet' on the western side (4 km long) and 'Puerto Real Inlet' on the eastern side $(3.3 \mathrm{~km}$ long). These are separated by Carmen Island (30 km in length and $2.5 \mathrm{~km}$ wide). The freshwater catchment of the lagoon consists of 3 main rivers: Palizada in the southwest, the Chumpan in the south and Candelaria in the southeast. The climate in this tropical region includes 3 main seasons: the winter storm season 'nortes' from October to January, the dry season from February to May, and the rainy season from June to September (Yáñez-Arancibia \& Day 1982).

Data were collated from 2 biological surveys in the Terminos lagoon, which were carried out monthly from February 1980 to April 1981 and from October 1997 to March 1999 (Ramos-Miranda et al. 2005); they were based on 18 and 23 sampling stations, respectively. In order to compare the assessments over space and time, only 17 sampling stations were selected for the 2 annual periods from February to January 1980 to 1981 and 1998 to 1999 (Fig. 1). Data from sampling stations were clustered according to the habitat units described in Yáñez-Arancibia \& Day $(1982,1988)$ and Ramos-
Fig. 1. Study area, sampling sites and 5 ecological subsystems (Areas A to E) as designated by Yáñez-Arancibia \& Day (1982) and Ramos Miranda (2000)

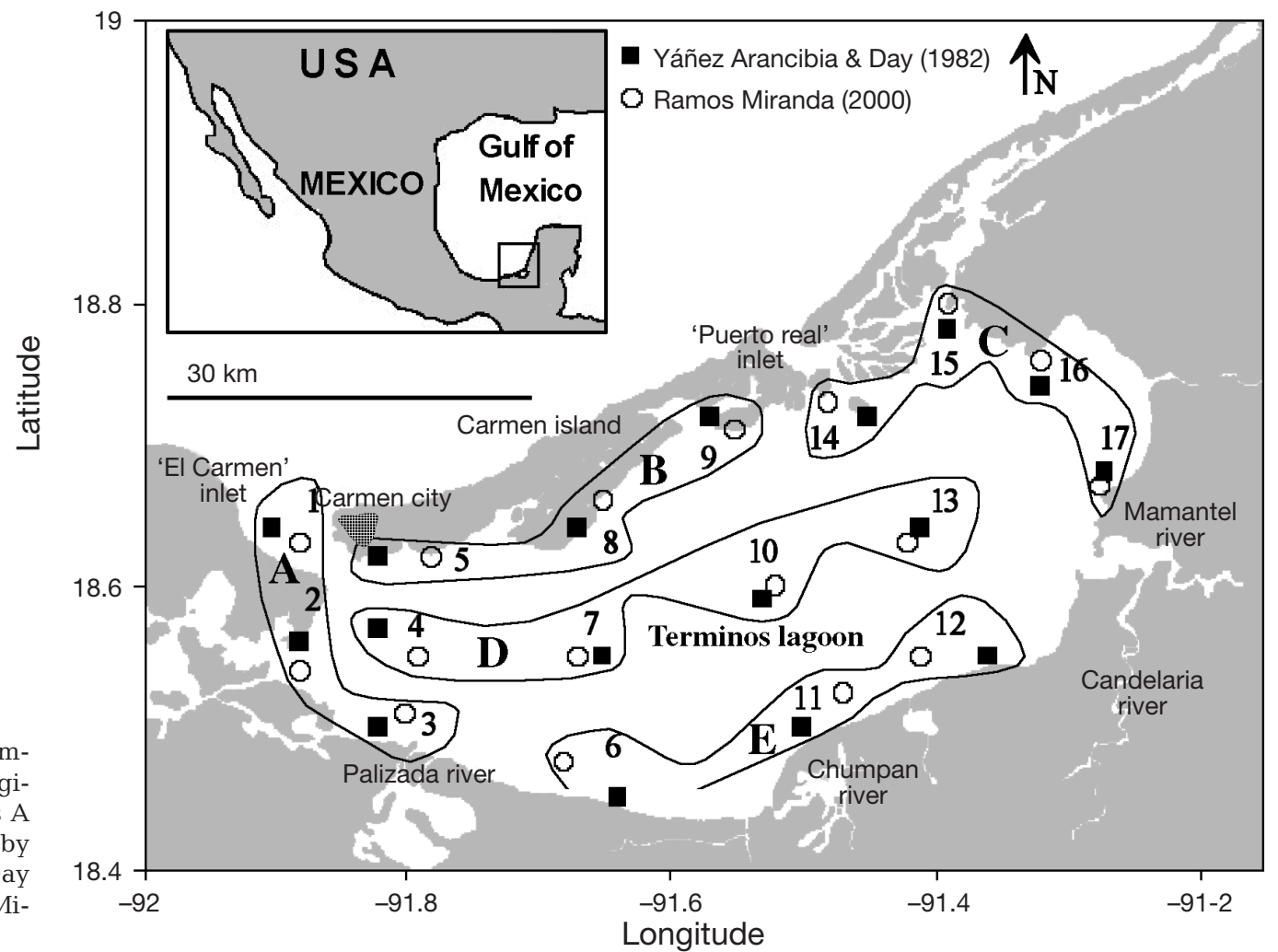


Miranda et al. (2000) (called areas in the present study; Fig. 1). Generally these areas have the following characteristics: Area A has highly variable freshwater inputs and the sediment is clay-silt with less than $30 \%$ $\mathrm{CaCo}_{3}$. This area includes mangrove swamps, macroalgae debris and oyster reefs. Area B has a strong sea water influence. The sediment is sand and silty-clay with 30 to $70 \% \mathrm{CaCo}_{3}$; macroalgae, seagrasses and mangrove swamps are also present. Area $\mathrm{C}$ has riverine influence; silty-clay sediment with 20 to $30 \%$ $\mathrm{CaCo}_{3}$ and seagrasses, mangrove swamps and oyster reef habitats. Area D is a transitional muddy zone with fine sand and clay-silt (30 to $40 \% \mathrm{CaCO}_{3}$ ). Area $\mathrm{E}$ is under a strong riverine influence with a silty-clay sediment (10 to $30 \% \mathrm{CaCo}_{3}$ ) and contains some mangrove swamps and oyster reefs.

For both surveys, fish were collected using a $5 \mathrm{~m}$ shrimp trawl (mouth opening diameter: $2.5 \mathrm{~m}$, mesh size: $19 \mathrm{~mm}$ ) with tows of $12 \mathrm{~min}$ at $2.5 \mathrm{knots}$; individual tows covered about $2000 \mathrm{~m}^{2}$. In order to obtain the best representation of the fish lagoon community and to reduce sampling bias due to selectivity (i.e. some species being more likely caught than others), an active fishing method (shrimp trawl net) rather than a passive method (e.g. trammel net) seemed more appropriate (e.g. Millar \& Fryer 1999). In the laboratory, fish species were then identified with reference to the taxonomic keys of Jordan \& Evermann (1886-1900), Hildebrand (1943), Fischer (1978), Castro-Aguirre (1978), and Resendez (1981 a,b). Taxonomic information (i.e. subphylum, class, order, suborder, family, genus and species) was completed using the FishBase electronic database (Froese \& Pauly 2003). All fish were counted and weighed to the nearest of 0.1 gram.

At each station, 4 environmental variables were recorded, i.e. depth $(\mathrm{cm})$, secchi depth $(\mathrm{cm})$, deep water temperature $\left({ }^{\circ} \mathrm{C}\right)$, and deep water salinity $(\%)$. In addition transparency $(t)$ was estimated from depth $(d)$ and secchi extinction $(s)$ as $t=100 \times(s / d)$.

Data analysis. To study changes in fish community structure of the Terminos lagoon between 1980 and 1998 we used 4 diversity indices each related to an independent facet of biodiversity. We classified the diversity indices with regard to whether they use presence/absence or abundance data and whether they use only species level information or the whole taxonomic tree (Fig. 2).

We implemented 2 complementary indices at the species level. The first one, species richness, is certainly the most widely used in ecology to assess environmental changes or to study community processes in multitrophic systems (e.g. McClanahan \& Arthur 2001). Due to the standard effort in the sampling method, estimation of this index may be considered to be standardized across the samples and therefore unbiased. The second index is an evenness index

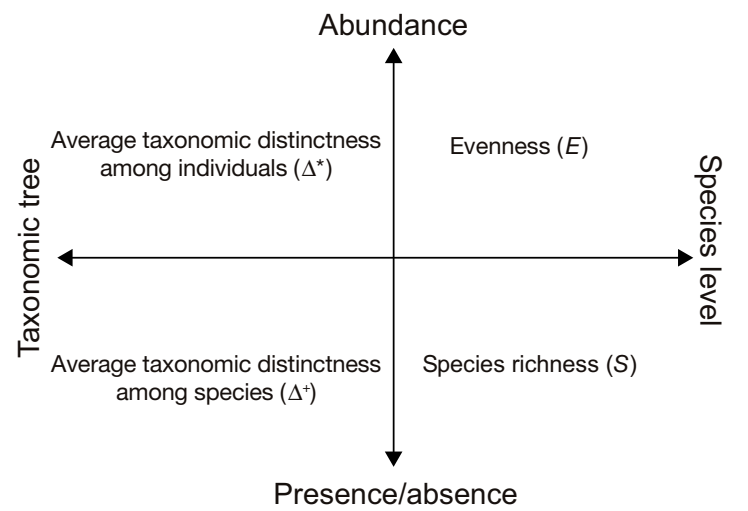

Fig. 2. Four complementary facets of diversity estimation according to abundance and taxonomic considerations

which provides information about the distribution of abundance among species independently of species richness. Among the multitude of proposed indices, we chose an evenness index meeting the 4 major requirements of Smith \& Wilson (1996) that is widely used and has a natural link with taxonomic diversity indices described thereafter: $E_{1 / D}$ is based on the index of species 'dominance' $D$ (Simpson 1949):

$$
E_{1 / D}=\frac{1 / \sum_{i=1}^{S} p_{i}}{S}
$$

where $S$ is the species number and $p_{i}$ is the frequency of the $i$ th species.

In animal ecology, the term species 'abundance' is often used as though it is synonymous with the number of individuals per unit area or volume, i.e. density. For example, in works on relative abundance distributions of free-living animals, density is used almost exclusively (Tokeshi 1993). However it is misleading to use density when this implies that an individual weighing a few grams has the same importance as an individual of several kilograms. This is particularly true when we study fish communities with large mean body size differences among species. Therefore we have to choose an 'abundance metric' in relation to the ecological process or the functional explanation of the process (Mouillot et al. 2001). In our study, we used species biomass rather than species density as it seems a more relevant way to consider the distribution of the resource apportioned by the species.

To establish taxonomic relationships between species Warwick \& Clarke $(1995,1998)$ and Clarke \& Warwick $(1998,2001)$ proposed a series of taxonomic diversity indices. The first diversity index, named the taxonomic diversity index $(\Delta)$, is formally defined as the average path length between every pair of individuals in the sample based on the taxonomic relationship between species (Warwick \& Clarke 1995). It can be 
seen as a generalization of the Simpson diversity index incorporating an element of taxonomic relatedness. The second index is a measure of taxonomic distinctness $\left(\Delta^{*}\right)$ which removes the evenness component from $\Delta$. We chose to use the second one in our study because it is more related to the pure taxonomic relatedness of individuals. The algebraic definition of average individual taxonomic distinctness $\left(\Delta^{*}\right)$ is:

$$
\Delta^{*}=\frac{\sum \sum_{i<j} \omega_{i j} X_{i} X_{j}}{\sum \sum_{i<j} X_{i} X_{j}}
$$

where $X_{i}(i=1, \ldots, s)$ denotes the abundance of the $i$ th species, $\omega_{i j}$ is the 'distinctness weight' given to the path length linking species $i$ and $j$ in the hierarchical classification, and the double summations are over all pairs of species $i$ and $j$.

When data are only presence/absence of species, $\Delta^{*}$ converges to the average specific taxonomic distinctness $\left(\Delta^{+}\right)($Clarke \& Warwick 1998, Warwick \& Clarke 2001) with the formula:

$$
\Delta^{+}=2 \frac{\sum \sum_{i<j} \Delta_{i j}}{S(S-1)}
$$

where $S$ is the species richness and $\Delta_{i j}$ is the 'distinctness weight' given to the path length linking species $i$ and $j$ in the hierarchical classification. When species are placed within a taxonomic hierarchy, based on the Linnean classification into phylum, class, order, family, genus and species, the average specific taxonomic distinctness, $\Delta^{+}$, is simply the mean number of steps up the hierarchy that must be taken to reach a taxonomic rank common to 2 species, computed across all possible pairs of species in an assemblage (Clarke \& Warwick 1998, 1999, Warwick $\&$ Clarke 2001). Thus, if 2 species are congeneric, 1 step (species-to-genus) is necessary to reach a common node in the taxonomic tree; if the 2 species belong to different genera but the same family, 2 steps will be necessary (species-to-genus, and genus-to-family); and so it goes on, with these numbers of steps averaged across all species pairs. Step lengths are standardized so that the distinctness of 2 species connected at the highest taxonomic level is set equal to 100 (Clarke \& Warwick 1999); $\Delta^{*}$ and $\Delta^{+}$are between 0 and 100 and positive. Both $\Delta^{*}$ and $\Delta^{+}$are supposed to be independent of the number of individuals and of species richness (Warwick \& Clarke 2001). As a consequence they add new information to the classical richness and evenness indices as they include differences between species (Fig. 2).

For each diversity index and each environmental variable we computed a 3-way ANOVA using area, season and year as independent factors (Zar 1984) with StatView software.

\section{RESULTS}

A total of 22834 individuals from 106 species were collected in 408 samples made monthly at both annual periods amounting to a total weight of $714.865 \mathrm{~kg}$. These species were classified into 72 genera, 41 families, 17 suborders, 15 orders and 2 classes.

\section{Diversity indices}

Three-factor ANOVA results for each of the 4 diversity indices using area, season and year as independent factors are showed in Table 1. Interactions between year and season and between year and area were significant $(\mathrm{p}<0.05)$ for the fish richness variable suggesting that the year effect on richness is not consistent among seasons and areas. Results obtained for the single factors highlighted the main influence of the area and season factors compared to the year factor on fish richness. Mean species richness was relatively higher on the edges of the lagoon (Areas A, B and C) than in the central basin (Areas D and E) whatever the season (Fig. 3). Richness reached a maximum of 27 fishes in Area B during the nortes season during the 1998 to 1999 period. The minimum fish richness (9) was observed in Area D during the dry season in the 1998 to 1999 period. Over all the areas, fish richness was relatively higher during the nortes season than during the 2 other seasons. Although evenness is a facet of biodiversity complementary to and independent of richness, ANOVA results were very similar to those obtained for richness, i.e. a stronger influence of season and area effects than of the year effect on fish community evenness. During the 1998 to 1999 period evenness was highest in Area B whatever the season. In contrast, during the 1980 to 1981 period, evenness was lowest in Area A during the dry and the rainy seasons, while it was highest in Area B whatever the season (Fig. 3).

Table 1. ANOVA $F$-values for 4 diversity facets and for 3 main factors and their interactions. $S$ : Species richness: $E$ : evenness: $\Delta^{*}$ : taxonomic distinctness among individuals; $\Delta^{+}$: taxonomic distinctness among species. ${ }^{N S}$ : non significant; ${ }^{*} p<0.05 ;{ }^{* *} p<0.01 ;{ }^{* * *} p<0.001$

\begin{tabular}{|lrcclc|}
\hline & df & \multicolumn{1}{c|}{$S$} & \multicolumn{1}{c|}{$E$} & $\Delta^{*}$ & $\Delta^{+}$ \\
\hline Zone & 4 & $15.62^{* * *}$ & $7.35^{* * *}$ & $2.16^{\mathrm{NS}}$ & $2.00^{\mathrm{NS}}$ \\
Year & 1 & $0.54^{\mathrm{NS}}$ & $1.72^{\mathrm{NS}}$ & $5.21^{*}$ & $23.31^{* * *}$ \\
Season & 2 & $27.99^{* * *}$ & $11.43^{* * *}$ & $0.94^{\mathrm{NS}}$ & $3.82^{*}$ \\
Zone $\times$ Year & 4 & $6.96^{* * *}$ & $3.16^{*}$ & $1.56^{\mathrm{NS}}$ & $3.65^{* *}$ \\
Zone $\times$ Season & 8 & $0.77^{\mathrm{NS}}$ & $2.84^{* *}$ & $1.49^{\mathrm{NS}}$ & $1.21^{\mathrm{NS}}$ \\
Year $\times$ Season & 2 & $3.54^{*}$ & $0.21^{\mathrm{NS}}$ & $0.42^{\mathrm{NS}}$ & $2.13^{\mathrm{NS}}$ \\
Zone $\times$ Year $\times$ Season & 8 & $1.08^{\mathrm{NS}}$ & $0.95^{\mathrm{NS}}$ & $2.49^{*}$ & $1.05^{\mathrm{NS}}$ \\
Error & 90 & & & & \\
Total & 119 & & & & \\
\hline
\end{tabular}



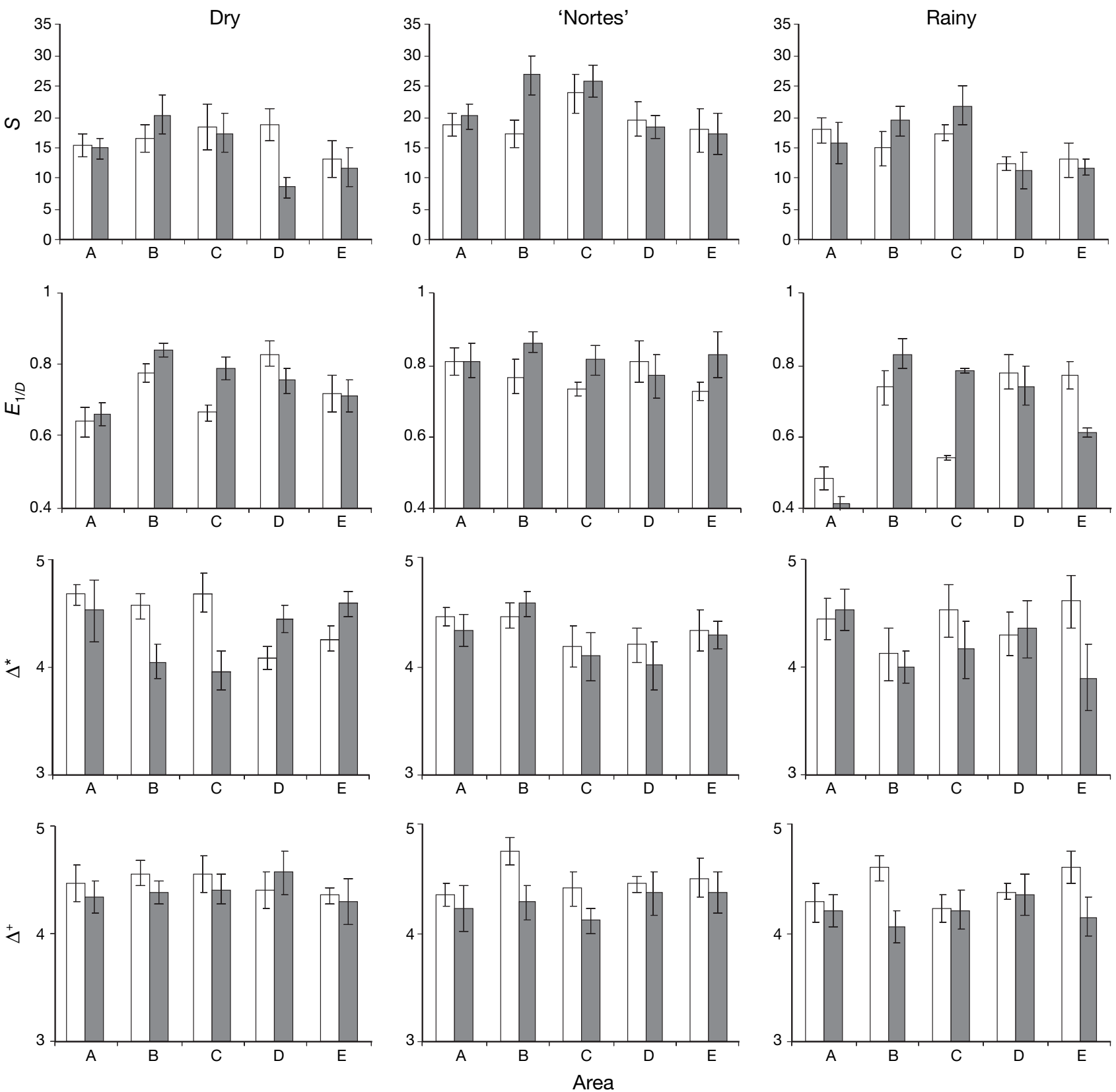

Fig. 3. Mean $( \pm \mathrm{SD})$ of the 4 diversity components $\left(S\right.$ : richness; $E_{1 / D}$ : biomass evenness; $\Delta^{*}$ : individual average taxonomic distinctness; $\Delta^{+}$: species average taxonomic distinctness) estimated over areas (A, B, C, D and E in Fig. 1), seasons and annual periods (1980 to 1981 in white and 1998 to 1999 in grey)

The observed variations of the 2 taxonomic diversity indices showed a different pattern to that obtained for the richness and evenness indices. For instance variation in $\Delta^{*}$ values was mainly explained by the year factor rather than by seasonal or area influences (Table 1). Overall, the mean $\Delta^{*}$ decreased from 4.40 ( $\mathrm{SE}=0.037$ ) in 1980 to 1981 to 4.25 ( $\mathrm{SE}=0.055$ ) in 1998 to 1999 indicating that on average coexisting fish individuals were taxonomically closer in 1998 to 1999 than in 1980 to 1981. This trend is particularly clear during the dry season (Fig. 3) in Area $\mathrm{C}$ where the mean taxonomic distance between 2 fish individuals dropped from 4.69 (between suborder and order) to 3.97 (between order and family). Variations in the index of average taxonomic distinctness among species $\left(\Delta^{+}\right)$were also explained mainly by the year factor even though the season significantly influenced this index (Table 1). In addition, the influence of area is not consistent with the year influence (significant interaction between the 2 factors): Area B presented the highest $\Delta^{+}$values during 
the 1980 to 1981 period while the Area E showed the highest $\Delta^{+}$values during the 1998 to 1999 period whatever the season (Fig. 3). Overall the average taxonomic distinctness among species dropped from 4.47 (SE $=$ $0.047)$ in 1980 to 1981 to 4.29 ( $\mathrm{SE}=0.092)$ in 1998 to 1999 suggesting that coexisting species became taxonomically more similar on average after $18 \mathrm{yr}$. To reinforce this result it is noticeable that mean $\Delta^{+}$values were always higher in 1980 to 1981 than in 1998 to 1999 except in Area D during the dry season (Fig. 3).

\section{Abiotic variables}

Results from the 3-factor ANOVAs carried out for 3 abiotic variables using area, season and year as independent factors are shown in Table 2. The most important differences were observed for salinity. Two interactions (Year $\times$ Season and Year $\times$ Zone) and the 3 single factors had a significant influence on salinity suggesting that salinity values were not homogeneously distributed among years, seasons and areas but were mainly dependent on lagoon heterogeneity, marine water entries and freshwater discharges. Not surprisingly, Area A, close to the freshwater intakes, showed the lowest salinity values whatever the season or the year (Fig. 4). Over all, the lowest salinity levels were measured during the nortes season whatever the year or area. The main result is the significant salinity increase from the 1980 to 1981 period $($ mean $=24.67 ; \mathrm{SD}=$ $7.74 \%$ ) to the 1998 to 1999 period $($ mean $=26.8$; $\mathrm{SD}=8.09 \%$ ). The temperature variable was also significantly influenced by the year, the season and the area factors as well as by the interaction between season and year factors suggesting that seasonal variations of this variable were not consistent between years (Table 2). The highest temperature values were always observed in Area E, the most confined one, whatever the year and the season (Figs. $1 \& 4$ ). The water temperature is also highest during the rainy season corresponding to the hottest season in North tropical countries. The

Table 2. ANOVA $F$-values for abiotic parameters and for 3 main factors and their interactions. ${ }^{\mathrm{NS}}$ : non significant; ${ }^{*} \mathrm{p}<0.05 ;{ }^{* *} \mathrm{p}<0.01 ;{ }^{* * *} \mathrm{p}<0.001$

\begin{tabular}{|lrccc|}
\hline & df & Salinity & Temperature & Transparency \\
\hline Zone & 4 & $32.32^{* * *}$ & $3.25^{*}$ & $26.16^{* * *}$ \\
Year & 1 & $13.71^{* * *}$ & $21.13^{* * *}$ & $25.91^{* * *}$ \\
Season & 2 & $149.80^{* * *}$ & $178.11^{* * *}$ & $1.17^{\mathrm{NS}}$ \\
Zone $\times$ Year & 4 & $2.43^{*}$ & $1.87^{\mathrm{NS}}$ & $2.02^{\mathrm{NS}}$ \\
Zone $\times$ Season & 8 & $0.87^{\mathrm{NS}}$ & $0.28^{\mathrm{NS}}$ & $1.23^{\mathrm{NS}}$ \\
Year $\times$ Season & 2 & $4.83^{* *}$ & $22.51^{* * *}$ & $3.44^{*}$ \\
Zone $\times$ Year $\times$ Season & 8 & $0.73^{\mathrm{NS}}$ & $0.13^{\mathrm{NS}}$ & $0.95^{\mathrm{NS}}$ \\
Error & 90 & & & \\
Total & 119 & & & \\
\hline
\end{tabular}

water temperature over the year increased between the 2 annual periods, from on average of $27.34^{\circ} \mathrm{C}$ (SD $=$ $\left.3.18^{\circ} \mathrm{C}\right)$ in 1980 to 1981 to $28.17^{\circ} \mathrm{C}\left(\mathrm{SD}=1.86^{\circ} \mathrm{C}\right)$ in 1998 to 1999 . This global increase is mainly due to the nortes season because the water temperature increased by $3^{\circ} \mathrm{C}$ between the 2 annual periods during this season (Fig. 4). For water transparency, the interaction between year and season factors was significant, assuming that seasonal variations of this variable were not consistent between years. If we consider single factors, the main differences observed in transparency values were due to area and year influences. For example, Area A, receiving freshwater discharge from the rivers (Fig. 1), always showed the lowest values whatever the season and the year (Fig. 4). Conversely areas with marine influences ( $\mathrm{B}$ and $\mathrm{C}$ ) had the highest transparency values. At the period level, the mean transparency increased from $35.16 \%(\mathrm{SE}=2.35)$ in 1980 to 1981 to $44.67 \%(\mathrm{SE}=3.47)$ in 1998 to 1999 . We can also observe that transparency values were always higher in 1998 to 1999 than in 1980 to 1981 except in Area B during the rainy season (Fig. 4).

\section{DISCUSSION}

\section{Changes in fish biodiversity}

Differences in species richness, biomass evenness, individual average taxonomic distinctness and species average taxonomic distinctness observed between areas, seasons and annual periods are influenced by both intrinsic community interactions and forcing environmental factors. For instance the local diversity of a community can be affected over relatively short periods of time by at least 4 types of factors: (1) the concentration of deleterious substances or physiologically severe conditions in the environment, (2) the abundance of key resources, (3) the abundance of key consumers or disturbances, and (4) specific features of the local environment (Valiela 1995).

Differences in richness and evenness are clearly associated to spatial and seasonal variability whereas these 2 diversity components are only weakly influenced by the year (Table 1). Moreover differences in richness and evenness are not consistent among areas, years and seasons (significant interaction effects). We can only observe that Areas B and C show the highest richness values in 1998 to 1999 whatever the season. These are the areas with the greatest marine influence and are therefore more likely to include marine species (especially snappers and small schoolers). 

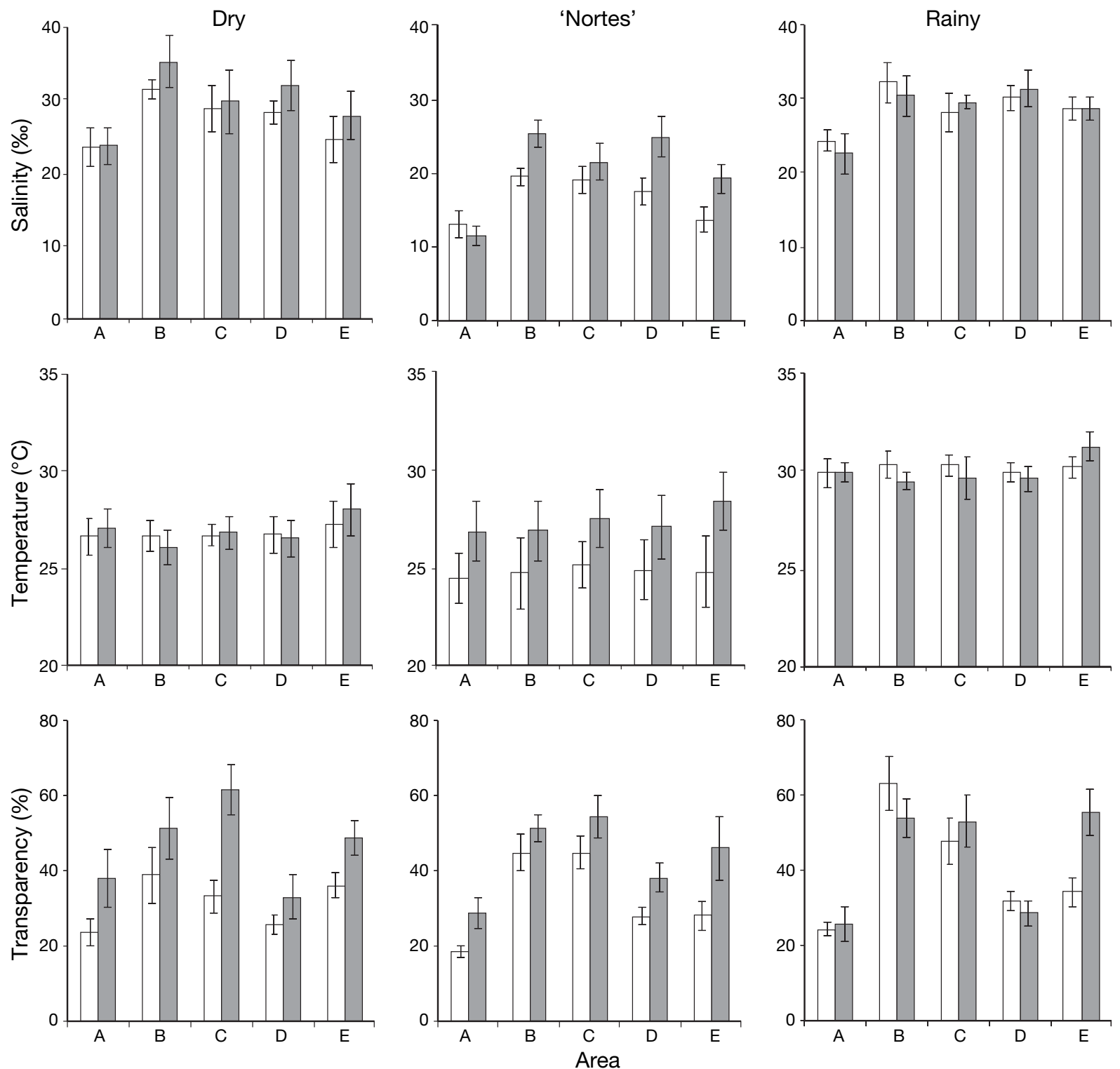

Fig. 4. Mean $( \pm \mathrm{SD})$ of 3 abiotic variables diversity components estimated over areas $(\mathrm{A}, \mathrm{B}, \mathrm{C}, \mathrm{D}$ and $\mathrm{E}$ in Fig. 1), seasons and annual periods (1980 to 1981 in white and 1998 to 1999 in grey)

In addition, the presence of artificial reefs, settled on the eastern coastal shelf (Fig. 1), should have contributed to increase marine fish richness, such as that reported in other coastal ecosystems (Santos \& Monteiro 1998). Species richness was also observed to be highest during the nortes season. This may be due to north winds enhancing intrusion of salt water into the lagoon (Areas B, C and D) followed by intrusion of marine species such as snappers (Lutjanidae). Any consistent trend was detected in evenness values during our study whatever the index used (we tried several but we present only results for the Simpson index $\left.E_{1 / D}\right)$. Our results confirm the low discrimination power of richness and evenness in environmental assess- ments (e.g. Danilov \& Ekelund 1999). These components of diversity are certainly influenced by many local and regional factors acting simultaneously over relatively short periods and independently from structural changes in ecosystem functioning (Blackburn \& Gaston 2002).

In contrast to the richness and evenness indices, the 2 taxonomic indices of fish community structure seem more related to long-term structural changes in ecosystems than to seasonal and small spatial-scale influences, as has already been demonstrated (Clarke \& Warwick 1998, Warwick et al. 2002). In our study, variations in the 2 average taxonomic distinctness indices were also clearly associated with the sampling period 
(Table 1): between 1980 to 1981 and 1998 to 1999, taxonomic diversity was reduced in the Terminos lagoon fish community, both in terms of average taxonomic distance among individuals $\left(\Delta^{*}\right)$ and in terms of average taxonomic distance among coexisting species $\left(\Delta^{+}\right)$. In others words, 2 randomly chosen individuals or 2 randomly chosen species within an assemblage were more likely to be close relatives in 1998 to 1999 than in 1980 to 1981. Nevertheless, the most important question is not whether a proposed diversity index satisfies some theoretical criterion or allows distinctions between field data communities but whether it proposes some functional interpretation about the causes and consequences of changes in observed assemblages. More details about community changes are provided in 2 recent papers using the same dataset (Ramos Miranda et al. 2005, Sosa Lopez et al. 2005)

\section{Causes of taxonomic diversity loss}

As early as 1859, Darwin (1859) pointed out that 'species of the same genus have usually, though by no means invariably, some similarity in habits and constitution', this similarity embracing morphological, lifehistory and functional traits. More recently, several studies have suggested that taxonomic structure and ecological similarity may be related in communities. For example, von Euler \& Svensson (2001) and Chazdon et al. (2003) reported that some functional traits are highly related to the taxonomy in birds and plants, respectively. With reference to fish communities, Vila-Gispert et al. (2002) demonstrated, through an intercontinental comparison, that taxonomic order and latitude are the 2 main factors explaining variations of life-history traits among species. In our study, we assume that ecological similarity (including many niche axes) is certainly conserved in fish lineages and that, using functional morphological attributes and reproductive life history traits, a negative correlation between ecological similarity and average taxonomic distance in fish communities would be found, i.e. that taxonomically related fishes are more likely to share some ecological attributes such as swimming capacity, trophic level and breeding period than taxonomically unrelated fishes. For instance, 4 snapper species from the same genus Lutjanus (L. analis, L. apodus, $L$. griseus and L. synagris) are all predators from a high trophic level and have part of their life cycle in coastal lagoons. The juveniles of the 4 snapper species have been reported as occasional visitors in Terminos lagoon. Even if some exceptions exist, this assumption seems generally realistic, i.e. ecological similarity tends to be higher among taxonomically related species through the niche conservatism process (Peterson et al. 1999). This general trend is consistent among a majority of groups of organisms (Webb et al. 2002). We are aware that true phylogenetic information (e.g. using molecular data) would be superior to mere taxonomic distance but this was impossible to obtain in our study.

A decrease in taxonomic diversity values may have different causes. Firstly, some environmental factors may act as niche filters allowing the presence of only some closely related species with particular biological attributes. For instance some closely related fish species in lakes and estuaries are either tolerant to eutrophic conditions or not (Ishitobi et al. 2000, Ludsin et al. 2001). Moreover, in a study of Mississippi river fishes, Bart et al. (1998) observed that differences in organic contaminant levels are related to taxonomy. More generally, if ecological niches are considered to be more similar among closely related species, an increasing magnitude of some environmental forces can lead to a decrease in the average taxonomic distance among individuals and/or species as illustrated in Fig. 5. We consider an environmental stress with an increasing intensity on a theoretical community with a perfectly even distribution of abundance on the taxonomic tree (step 1). This stress does not have a random impact on each species but species belonging to the family $F_{\mathrm{a}}$ are more likely to suffer from this stress than

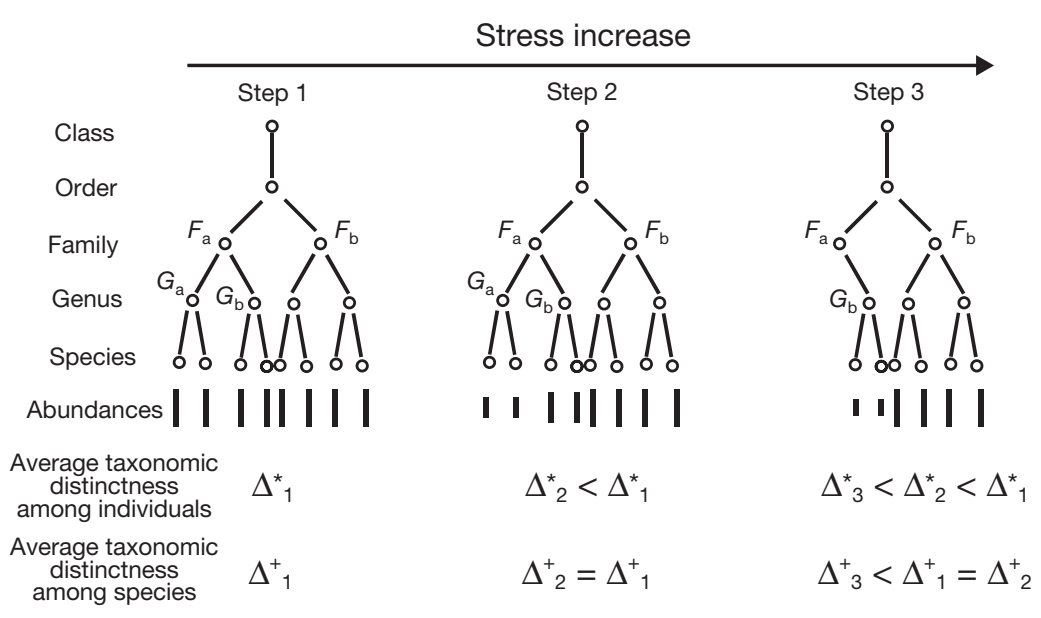

Fig. 5. Theoretical evolutions of 2 taxonomic diversity indices $\left(\Delta^{*}, \Delta^{+}\right)$of a community along a stress gradient such as an environmental variable, a toxic level or habitat destruction. This community has 8 equally abundant species belonging to 4 genera and 2 families and one order at Step 1. The stress is acting more strongly on species belonging to Family a $\left(F_{\mathrm{a}}\right)$ than on species belonging to Family $\mathrm{b}\left(F_{\mathrm{b}}\right)$ and more strongly on species belonging to Genus a $\left(G_{\mathrm{a}}\right)$ than on species belonging to Genus b $\left(G_{\mathrm{b}}\right)$. As a consequence abundance of species belonging to Genus a decreases and disappears leading to a decrease in $\Delta^{*}$ values and then to a decrease in $\Delta^{+}$values 
species belonging to the family $F_{\mathrm{b}}$. As a consequence the species belonging to $F_{\mathrm{a}}$ are more likely to decrease in abundance and to disappear leading to a decrease in taxonomic diversity of the initial assemblage. The second main cause of a decrease in taxonomic diversity of local communities is a local heterogeneity loss in terms of habitat and resource. Closely related species are assumed to use similar habitat and resources, thus a loss of local heterogeneity may limit the number of niches available and thus decrease the level of taxonomic differences within communities (Fig. 5). Conversely, higher resource and habitat diversity is supposed to promote higher taxonomic diversity levels in local communities because it would enhance the coexistence of weakly related species with contrasting ecological requirements.

In the Terminos lagoon, the observed changes in the fish taxonomic structure could be influenced by at least 4 main external forcing factors: (1) fishing activities, (2) pollutants, (3) habitat degradation and (4) loss of estuarine conditions.

(1) Although fishing activities have been forbidden in the lagoon since 1994, artisanal shrimp trawlers are still present, particularly in the outlets of Palizada and Chumpan rivers and Atasta estuary (see Fig. 1). In addition, there is an increasing fishing intensity that occurs on the western continental shelf adjacent to the lagoon. Fishing has long been associated with a decrease in the mean fish size (e.g. Rogers et al. 1999) as well as changes in species richness and composition (e.g. Rice \& Gislason 1996). Moreover, different taxa do not have the same sensitivity to commercial trawl fisheries and some families and orders share some lifehistory characteristics which make them more susceptible to fishing than others. As a consequence, the remaining species and individuals are more likely to be taxonomically close and the taxonomic diversity indices are expected to decrease, as was demonstrated by Rogers et al. (1999) in coastal waters of NW Europe with elasmobranch fishes. If we consider the fishing intensity as a stress, this is comparable to the effect of the increasing magnitude of environmental forces depicted in Fig. 5. In our study, Sciaenidae, Aridae and Gerridae families contain species reported as dominant in the 1980 to 1981 period but as rare in the 1998 to 1999 period.

(2) The Terminos lagoon has been affected by largescale anthropogenic influences, mainly the substantial development of the oil industry, the increasing agricultural activities on the watershed, and the increasing population on Carmen Island (Currie-Alder 2001). According to Carvalho (2002), persistent pollutants (e.g. those included in pesticides) of an agricultural source were identified in the Terminos lagoon, which accumulate at several trophic levels. Rendon-von
Osten \& Memije (2001) reported that several persistent organochlorine pesticides such as DDT were present in the lagoon; they found low concentration of these pesticides in the white shrimp Litopenaeus setiferus which is an important portion of the diet of some fishes, mainly from Sciaenidae, Aridae and Lutjanidae families. Thus, anthropogenic activities such as agricultural, fishing and oil activities which are growing in the Terminos lagoon's adjacent marine zone can in part explain the non-occurrence of the more pollutionsensitive species and the recent occurrence of the more pollution-tolerant species such as detritivorous fishes (Sosa Lopez et al. 2005). As a consequence, the compounds in polluted waters draining toward Terminos lagoon can affect the taxonomic structure of fish communities, causing a decreasing taxonomic distance on average among coexisting individuals and coexisting species (Fig. 5).

(3) The loss of submerged vegetation, which usually provides supplementary ecological niches and thus allows coexistence of species with very different ecological requirements, may partly explain the loss of taxonomic diversity. In the Terminos lagoon, Villalobos Zapata et al. (2002) indicated that seagrass areas have decreased significantly in the inner shore of the Carmen island due to 3 factors: impact of Hurricane Roxane in 1995, increase of urban activities leading to an increasing nutrient level in the system, and sand extraction in the inner shore of Carmen Island and Boca de Puerto Real. As a consequence, local fish communities are more ecologically similar after $18 \mathrm{yr}$ in the Terminos lagoon, which may explain the loss of taxonomic diversity among individuals and among species.

(4) Abiotic factors analyses unambiguously highlight the loss of estuarine conditions in the Terminos lagoon between the 1980 to 1981 period and the 1998 to 1999 period (Table 2, Fig. 4), i.e. an increasing water transparency coupled with an increasing salinity. This process has been occurring over a long time period since the 1950s and is still observed: salinity and transparency also increased in 2001 to 2002 (Villalobos Zapata et al. 2002). A shift in hydrological conditions has been reported from hypohaline to euhaline/hyperhaline status (Villalobos Zapata et al. 2002). These hydrological changes allow us to assume that some fish families such as Mugilidae, Serranidae, Lobotidae, Achiridae, Belonidae, Elopidae and Stromatide are recently better represented within Terminos lagoon than in the past. Indeed, most of the present species belong to these former families, while some orders or families are less abundant or are absent in some samples leading to a decrease in the average taxonomic relatedness between individuals or coexisting species. Moreover, changes in hydrological patterns such as an increase in the influx of seawater into the lagoon have 
restricted the estuarine species distribution to riverrunoff areas (i.e. Areas A and E). This observation is particularly evident for Area C where the transparency increased from 33.37 in 1980 to 1981 to 61.61 in 1998 to 1999 (Fig. 4) during the dry season. At the same time the mean taxonomic distance between 2 random fish individuals dropped from 4.69 (between suborder and order) to 3.97 (between order and family) revealing that individuals were much more closely related and therefore likely to be more ecologically similar in 1998 to 1999 than in 1980 to 1981 . For instance, some species such as Anchoa mitchilli, Ancyclopsetta quadrocellata, Eucinostomus melanopetheros, Cynoscion nebulosus and $C$. nothus were present in this area during the dry season in 1980 to 1981, while they were absent in the latter sampling. These species increased taxonomic diversity through addition of particular families and orders such as Engraulidae (order Cupleiformes) and Paralichtydae (order Pleuronectiformes). In Area E, we also observed an increase in transparency level during the rainy season after 18 yr (from 34.36 in 1980 to 1981 to 55.43 in 1998 to 1999 ). In parallel, the taxonomic diversity among individuals and among species decreased significantly between the 2 annual periods in this area during the rainy season (Fig. 3), while the richness was about the same (13 species on average in 1980 to 1981 versus 12 species on average in 1998 to 1999). More individuals and more species were closely related in 1998 to 1999 than in 1980 to 1981. For instance, some families were more widely represented in 1998 to 1999 than in 1980 to 1981 (Gerridae, Carangidae and Lutjanidae); some particular estuarine taxon were less represented in 1998 to 1999 than in 1980 to 1981, such as Ariopsis felis (Aridae), Bairdiella chrysoura, Cynoscion nothus, C. nebulosus (Sciaenidae), Sphoeroides marmoratus and $S$. testudineus (Tetodontidae).

\section{Consequences of taxonomic diversity loss}

A decrease in the taxonomic diversity can have a number of consequences on ecosystems implying that the net ecological similarity among species and among individuals within local assemblages increases. The greater the net ecological similarity within the community, the lower the level of variation in biological responses that can be expected during a perturbation or a crisis event. Ecosystems are usually impacted by strong events and perturbations such as dystrophic crisis in coastal lagoons (Bachelet et al. 2000). With species from different lineages we can expect different biological responses to perturbations through various life-history traits or physiological abilities and thus a higher stability or resilience of the biotic compartment.
Moreover, the taxonomic homogenization observed locally induces a simplification of the food web (Olden et al. 2004) because taxonomically related species are generally assumed to consume similar resources. Conversely, the more taxonomically unrelated the species are, the more the ecological similarity decreases within the community and the greater the level of complexity that can be maintained in the food web. The susceptibility of communities to species invasions has also been related to niche processes in both marine and terrestrial ecosystems (Dukes 2002, Stachowicz et al. 2002). The underlying theory is that communities composed of species occupying different ecological niches are less susceptible to invasion because a large spectrum of resources (spatial, temporal and nutrients) are already apportioned and few resources remain available for invaders (Olden et al. 2004). Thus, for the same number of species, a lower net ecological similarity within the community (higher taxonomic and functional diversity) can limit the probability of invasion (Dukes 2002). If we consider that niche conservatism occurs through lineages, a local assemblage composed of closely related species is expected to present some functional similarities, such as a temporal synchrony in recruitment for fish. This lack of complementary use of resources in time could facilitate fish invasion. The last consequence concerns the aesthetic value of the local community. The more the species are taxonomically unrelated, the more varied are body shapes, colors or behaviors that can be observed, with a corresponding increase in the aesthetic value of the ecosystem. Thus a loss of taxonomic diversity is also expected to induce a loss in the aesthetic value of fish assemblage which can provide valuable income for local populations through the ornamental fish business (Pelicice \& Agostinho 2005).

\section{CONCLUSION}

It is well recognized that natural environmental variations drive changes in fish abundance and diversity in coastal lagoons (Bachelet et al. 2000, Ishitobi et al. 2000). Nevertheless the different components of biodiversity can be influenced in a totally different way and at different spatio-temporal scales. Using experimental fish surveys in a tropical coastal lagoon, our study demonstrates that species richness and biomass evenness are more influenced by seasonal and spatial factors than by inter-annual differences even after 18 yr. Conversely, the diversity indices based on the taxonomic structure of assemblages have clearly decreased after $18 \mathrm{yr}$, indicating a loss of taxonomic diversity whatever the season or the zone. As a consequence, this loss of taxonomic diversity can lead to a 
loss of ecological responsiveness to environmental fluctuations and a loss of ecological functions providing goods and services to ecosystems. However, we may wonder whether a reduction in taxonomic distinctness over this $18 \mathrm{yr}$ period is really part of a long term trend, which would be cause of concern, or simply represents inter-annual variability, the value of taxonomic distinctness possibly increasing and decreasing over this time period. Accordingly, we recommend a biannual monitoring scheme based on fish presence/absence records in order to assess the environmental pressures on the Terminos lagoon ecosystem coupled with the monitoring of the main abiotic variables driving diversity.

Acknowledgements. We thank SISIERRA-CONACYT for financial support of this research project (ALIM-11-96). Three anonymous reviewers made very useful and constructive comments. B. J. Anderson considerably improved the manuscript.

\section{LITERATURE CITED}

Airoldi L, Cinelli F (1997) Effects of sedimentation on subtidal macroalgal assemblages: an experimental study from a Mediterranean rocky shore. J Exp Mar Biol Ecol 215: 269-288

Bachelet G, de Montaudouin X, Auby I, Labourg PJ (2000) Seasonal changes in macrophyte and macrozoobenthos assemblages in 3 coastal lagoons under varying degrees of eutrophication. ICES J Mar Sci 57:1495-1506

Bart HL, Martinat PJ, Abdelghani A, Tchounwou PB, Taylor SL (1998) Influence of taxonomy, ecology, and seasonality in river stage fish contamination risks in floodplain swamps of the lower Mississippi river. Ecotoxicology 7 : 325-334

Bellwood DR, Hughes TP, Folke C, Nystrom M (2004) Confronting the coral reef crisis. Nature 429:827-833

Blackburn TM, Gaston KJ (2002) Scale in macroecology. Global Ecol Biogeogr 11:185-189

Carrasson M, Cartes JE (2002) Trophic relationships in a Mediterranean deep-sea fish community: partition of food resources, dietary overlap and connections within the benthic boundary layer. Mar Ecol Prog Ser 241:41-55

Carvalho FP (2002) Tropical and sub-tropical cost-effective tools for an integrated risk assessment of wetlands (TROCA). European Union Research Contract. IC18-CT98-0264 (DGXII-CPDE). Final Report of the Sub-Contractor. Instituto Tecnológico e Nuclear. Departamento de Proteccao Radiológica e Seguranca Nuclear. Sacavém

Castro-Aguirre JL (1978) Catálogo sistemático de los peces marinos que penetran a las aguas continentales de México con aspectos zoogeográficos y ecológicos. Serie Científica, Dir Gral Inst Nal Pesca, México

Chazdon RL, Careaga S, Webb C, Vargas O (2003) Community and phylogenetic structure of reproductive traits of woody species in wet tropical forests. Ecol Monogr 73: 331-348

Clarke KR, Warwick RM (1998) A taxonomic distinctness index and its statistical properties. J Appl Ecol 35:523-531

Clarke KR, Warwick RM (1999) The taxonomic distinctness measure of biodiversity: weighting of step lengths be- tween hierarchical levels. Mar Ecol Prog Ser 184:21-29

Clarke KR, Warwick RM (2001) A further biodiversity index applicable to species lists: variation in taxonomic distinctness. Mar Ecol Prog Ser 216:265-278

Costanza R, Darge R, Degroot R, Farber S and 9 others (1997) The value of the worlds ecosystem services and natural capital. Nature 387:253-260

Crooks S, Turner RK (1999) Integrated coastal management: Sustaining estuarine natural resources. Adv Ecol Res 29: 241-289

Currie-Alder BAB (2001) Collaborative management of the Mexican coast: Public participation and the oil industry in the Terminos Lagoon Protected Area. MSc thesis, Simon Fraser University, Burnaby, BC

Danilov R, Ekelund NGA (1999) The efficiency of seven diversity and one similarity indices based on phytoplankton data for assessing the level of eutrophication in lakes in central Sweden. Sci Total Environ 234:15-23

Darwin C (1859) The origin of species by means of natural selection. Murray, London

Dukes JS (2002) Species composition and diversity affect grassland susceptibility and response to invasion. Ecol Appl 12:602-617

FAO (Food and Agriculture Organisation) (2002) The State of World. Fisheries and Agriculture. FAO, Rome

Fischer W (1978) FAO species identification sheets for fishery purposes. Western Central Atlantic (Fishing Area 31). FAO, Rome

Froese R, Pauly D (eds )(2003) Fishbase. World wide web electronic publication. www.fishbase.org, version 16, March 2004

Gaston KJ (1996) Biodiversity. Blackwell, Oxford

Hildebrand SF (1943) A review of the American anchovies (Engraulidae). Bull Binham Oceanogr Collect Yale Univ 8: $1-165$.

Hillebrand H (2003) Opposing effects of grazing and nutrients on diversity. Oikos 100:592-600

Ishitobi Y, Hiratsuka J-i, Kuwabara H, Yamamuro M (2000) Comparison of fish fauna in 3 areas of adjacent eutrophic estuarine lagoons with different salinities. J Mar Syst 26: 171-181

Jordan DS, Evermann BW (1886-1900). The fish of north and middle America. Bull US Nat Mus 1-4:1-3313

Lasserre G (1979) Coastal lagoons sanctuary ecosystems, cradles of culture, targets for economic growth. Nat Resour $15: 2-21$

Levin LA, Boesch DF, Covich A, Dahm C and 8 others (2001) The function of marine critical transition zones and the importance of sediment biodiversity. Ecosystems 4: $430-451$

Ludsin SA, Kershner MW, Blocksom KA, Knight RL, Stein RA (2001) Life after death in Lake Erie: nutrient controls drive fish species richness, rehabilitation. Ecol Appl 11:731-746

Ludwig JA, Reynolds JF (1988) Statistical ecology. A primer on methods and computing. Wiley, New York

McClanahan TR, Arthur R (2001) The effect of marine reserves and habitat on populations of east African coral reef fishes. Ecol Appl 11:559-569

Millar RB, Fryer RJ (1999) Estimating the size-selection curves of towed gears, traps, nets and hooks. Rev Fish Biol Fish 9:89-116

Mouillot D, Titeux A, Migon C, Sandroni V, Frodello JP, Viale D (2000) Anthropogenic influences on a mediterranean Nature Reserve: modelling and forecasting. Environ Model Assess 5:185-192

Mouillot D, Culioli JM, Wilson JB, Frodello JP, Mouillot F, Lepretre A, Marchand B (2001) Number, length, area or 
biomass: Can there be intermediates? Ecoscience 8: 264-267

Olden JD, Poff NL, Douglas MR, Douglas ME, Fausch KD (2004) Ecological and evolutionary consequences of biotic homogenization. Trends Ecol Evol 19:18-24

Pelicice FM, Agostinho AA (2005) Perspectives on ornamental fisheries in the upper Parana River floodplain, Brazil. Fish Res 72:109-119

Peterson AT, Soberon J, Sanchez-Cordero V (1999) Conservatism of ecological niches in evolutionary time. Science 285:1265-1267

Purvis A, Hector A (2000) Getting the measure of biodiversity. Nature 405:212-219

Ramos-Miranda J (2000) Exploitation de la Crevette blance Litopenaeus setiferus en Campeche, Mexique. $\mathrm{PhD}$ thesis, University of Bretagne Occidentale

Ramos-Miranda J, Quiniou L, Flores-Hernandez D, Do-Chi T, Ayala-Perez L, Sosa-Lopez A (2005) Spatial and temporal changes in the nekton of the Terminos Lagoon, Campeche, Mexico. J Fish Biol 66:513-530

Rendón-von Osten J, Memije M (2001) Persistent organochlorine pesticide as biomarker of exposure in white shrimp (L. setiferus) from Terminos lagoon, Campeche, Mexico. Abstract Book: Biomarkers of Environmental Contamination, Porto

Resendez Medina A (1981a) Estudio de los peces de la Laguna de Terminos, Campeche, Mexico I. Biótica 6: 239-291

Resendez Medina A (1981b) Estudio de los peces de la Laguna de Terminos, Campeche, Mexico II. Biótica 6:345-430

Rice J, Gislason H (1996) Patterns of change in the size spectra of numbers and diversity of the North Sea assemblage, as reflected in surveys and models. ICES J Mar Sci 53: 1214-1225.

Rogers SI, Clarke KR, Reynolds JD (1999) The taxonomic distinctness of coastal bottom-dwelling fish communities of the North-east Atlantic. J Anim Ecol 68:769-782

Santos MN, Monteiro CC (1998) Comparison of the catch and fishing yield from an artificial reef system and neighbouring areas off Faro (Algarve, South Portugal). Fish Res 39:55-65

Shimatani K (2001) On the measurement of species diversity incorporating species differences. Oikos 93:135-147

Simpson EH (1949) Measurement of species diversity. Nature 163:688

Smith B, Wilson JB (1996) A consumer's guide to evenness indices. Oikos 76:70-82

Sosa-Lopez A, Mouillot D, Chi TD, Ramos-Miranda J (2005)

Editorial responsibility: Howard I. Browman (Associate

Editor-in-Chief), Storebø, Norway
Ecological indicators based on fish biomass distribution along trophic levels: an application to the Terminos coastal lagoon, Mexico. ICES J Mar Sci 62:453-458

Stachowicz JJ, Fried H, Osman RW, Whitlatch RB (2002) Biodiversity, invasion resistance, and marine ecosystem function: reconciling pattern and process. Ecology 83: $2575-2590$

Tokeshi M (1993) Species abundance patterns and community structure. Adv Ecol Res 24:111-186

Valiela I (1995) Marine ecological processes, 2nd edn. Springer, New York

Vila-Gispert A, Moreno-Amich R, Garcia-Berthou E (2002) Gradients of life-history variation: an intercontinental comparison of fishes. Rev Fish Biol Fish 12:417-427

Villalobos Zapata G, Palacio Aponte G, Sosa López A, Alvaez Guillén H, Reda Deara A (2002) Ecología del paisaje y Diagnóstico Ambiental del ANP 'Laguna de Términos'. Informe Final. SISIERRA P/SISIERRA 20000706030

von Euler F, Svensson S (2001) Taxonomic distinctness and species richness as measures of functional structure in bird assemblages. Oecologia 129:304-311

Warwick RM, Clarke KR (1995) New 'biodiversity' measures reveal a decrease in taxonomic distinctness with increasing stress. Mar Ecol Prog Ser 129:301-305

Warwick RM, Clarke KR (1998) Taxonomic distinctness and environmental assessment. J Appl Ecol 35:532-543

Warwick RM, Clarke KR (2001) Practical measures of marine biodiversity based on relatedness of species. Oceanogr Mar Biol 39:207-231

Warwick RM, Ashman CM, Brown AR, Clarke KR and 6 others (2002) Inter-annual changes in the biodiversity and community structure of the macrobenthos in Tees Bay and the Tees estuary, UK, associated with local and regional environmental events. Mar Ecol Prog Ser 234:1-13

Webb CO, Ackerly DD, McPeek MA, Donoghue MJ (2002) Phylogenies and community ecology. Annu Rev Ecol Systemat 33:475-505

Yáñez-Arancibia A, Day JW Jr (1982) Ecological characterization of Terminos Lagoon, a tropical lagoon-estuarine system in the southern Gulf of Mexico. Oceanol Acta 5: $431-440$

Yáñez-Arancibia A, Day JW Jr (1988) Ecology of coastal ecosystems in the Southern Gulf of Mexico: The Terminos Lagoon Region. Inst Cienc Del Mar y Limnol UNAM, COSAT Ecol Inst LSU. Editorial Universitaria, Mexico DF

Zar JH (1984) Biostatistical analysis. Prentice-Hall International Editions, Englewood Cliffs, NJ

Submitted: June 15, 2005; Accepted: September 1, 2005

Proofs received from author(s): November 12, 2005 